
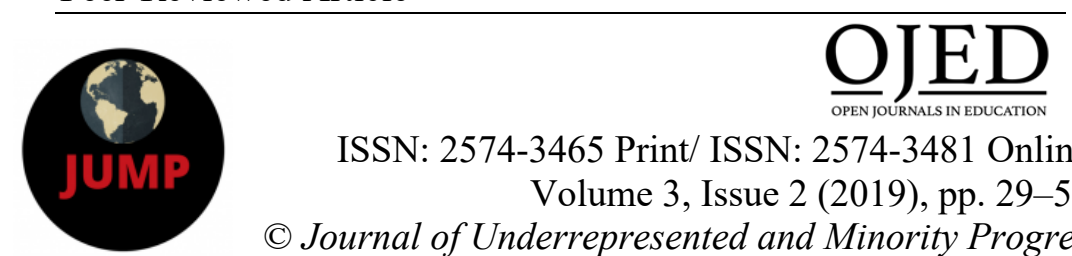

ISSN: 2574-3465 Print/ ISSN: 2574-3481 Online

Volume 3, Issue 2 (2019), pp. 29-50

(C) Journal of Underrepresented and Minority Progress

http://ojed.org/jump

\title{
Understanding Indian International Student Experience in the United States
}

\author{
Prashanti Chennamsetti \\ Texas A \& M University, USA \\ Krishna Bista \\ Morgan State University, USA
}

\begin{abstract}
Currently, over 196,271 Indian international students are attending American colleges and universities. These students, similar to other ethnic minority student populations, encounter various challenges while studying overseas. This article focuses on two central questions, (1) How do individual factors (e.g., personality traits) of Indian international students aid in their adjustment in the U.S? (2) Can these individual factors be acquired? Seven Indian international students currently studying in a U.S. university were interviewed. Data were analyzed using phenomenological methodology. The findings identified ten individual themes that aided in adjustment and reported how these factors can be acquired by adapting certain cognitive and behavioral aspects. This study reflects the limitations, implications, and future research.
\end{abstract}

Keywords: Minority students, Indian international students, adjustment, interpersonal relations, phenomenology, Asian international students, individual factors 


\section{INTRODUCTION}

According to the Institute of International Education (IIE, 2018), currently, 196,271 Indian international students are attending American colleges and universities. However, international students, like other ethnic minorities inthe U.S. higher education system, experience various challenges (Bista, 2012; Wei, Ku, Russell, Mallinckrodt, \& Liao, 2008; Yeh \& Inose, 2003). For instance, an Indian student participant in a qualitative study (Lee \& Rice, 2007) shared her personal experience: "I'm uncomfortable with the [U.S.] culture here...I don't say it's bad, it's obviously good that's why it is still there, but I'm uncomfortable with this type of culture" (p. 397). In another qualitative study, Kaur (2006) reported aspects such as English language and unfamiliar academic system causing difficulties for Asian students in adjusting to the U.S. higher education communities.

Previous literature reported various factors that influenced international student adjustment, one of those being the individual factors (e.g. Hendrickson, Rosen, \& Aune, 2011). Individual factors refer to the students' personalities, perceptions, and attitudes towards host country and host nationals (Mori, 2000; Poulakis, Dike, \& Massa, 2017; Ward, Bochner, \& Furnham, 2001). Past studies identified several aspects that are considered as individual factors, namely sense of belongingness, ability to interact socially, English language speaking abilities, and personality traits (Chavoshi, Wintre, Dentakos \& Wright, 2017; Hirai, Frazier, \& Syed, 2015; Martinez \& Colaner, 2017; Zhou \& Cole, 2017).

To possess a higher sense of belongingness, one of the integral factors is to interact socially with the host nationals (Hendrickson, Rosen, $\&$ Aune, 2011). For successful interaction, Ying (2002) emphasized on having a positive attitude, as such approach encourages feelings of social connectedness, satisfaction, and contentment (Duru \& Poyrazli, 2007; Hendrickson, et al, 2011; Poyrazli, Kavanaugh, Baker \& Al-Timimi, 2004). International students with more host national friends reported less loneliness (Hendrickson, et al, 2011) and successful adjustment to the host culture (Chavoshi, et al, 2017; Hirai et al, 2015; Li \& Gasser, 2005; Shupe, 2007). Apart from forming friendships with host nationals, those students who invested more time trying to understand the host country reported enhanced relationships with the host nationals (Gomez, Urzua \& Glass, 2014; Ying, 2002). On the other hand, limited social contact with the host 
nationals led to limited survival skills in the host country (Rui \& Wang, 2015).

Although the formation of friendships with the host nationals is crucial for successful cross-cultural adjustment, Sam (2001) suggested it to be difficult, one of the inherent barriers being the language. Some international students in the U.S. experience difficulty in understanding the American accent and local expressions (Mori, 2000; Yeh \& Inose, 2003). They develop communication anxiety and are unable to express thoughts appropriately (Alsahafi \& Shin, 2016). On the other hand, students with higher levels of English proficiency experience lower levels of acculturative stress (Martinez \& Colaner, 2017; Poyrazli et al, 2004). Focusing on perceptions, Robertson, Line, Jones, and Thomas (2000) reported that more than the actual English-speaking abilities, perceptions of having lower English-speaking skills deters the students from actively participating in classroom discussions, thereby negatively impacting their academic performance. In a similar study, it was found that when students felt underconfident, nervous, embarrassed or fearful of their Englishspeaking abilities, they reported significant levels of depression, difficulty in interacting socially and in overall adjustment (Swagler \& Ellis, 2003).

Further, researchers explored the impact of personality traits, that is, neuroticism, extraversion, agreeableness, and conscientiousness on cross-cultural adjustment. Such research helped in understanding how international students perceive, act, cope and adjust to the transitional stress (Magnus, Diener, Fujita, \& Pavot, 1993). Neuroticism includes the aspects of anxiety, hostility, depression, self-consciousness, and vulnerability; Extraversion consists of the facets of assertiveness, activeness, and cheerfulness; Conscientiousness includes competence, order, dutifulness, achievement-striving, self-discipline, and deliberation; and Agreeableness covers aspects of trust, straightforwardness, altruism, compliance, modesty, and tender-mindedness (Costa \& McCrae, 1995; Gershuny \& Sher, 1998; Searle \& Ward, 1990; Swagler \& Jome, 2005; Ying, 2002). Past studies consistently indicated neuroticism to cause more cross-cultural adjustment problems (Costa \& McCrae, 1995; Duru \& Poyrazli, 2007; Hirai et al, 2015; Swagler \& Jome, 2005). Neurotic individuals were found to experience irrational thoughts, impulsiveness (Costa \& McCrae, 1995), global anxiety, and depression (Gershuny \& Sher, 1998). They were reported to be "fearful and perceive that they are not easily accepted by the people in the host culture. They perceive more discrimination, hate/rejection, fear, and homesickness" in the host country (Poyrazli, Thukral, \& Duru, 2010, p. 29). Extravert students were reported to possess better interpersonal relations and enhanced psychological well-being (Searle \& Ward,1990). The 
research suggested that students who were more extravert, conscientious and agreeable, experienced higher psychological and sociocultural adaptation as they used more coping methods, such as problem-solving, planning, and thinking positively (Roesch, Wee, \& Vaughn, 2006; Ward, Leong \& Low, 2004). Conversely, students who were not agreeable or conscientious experienced psychological difficulties such as depression, substance abuse, and social problems (Swagler \& Jome, 2005).

While a large amount of research on cross-cultural adjustment is often focused on international students as a group, students from India are less explored, though they are the second largest among the international student population in the U.S. Additionally, this study focused exclusively on students from India to acknowledge their sociocultural or geographical differences from other Asian international students. Thus, the purpose of this study is to explore two questions, (1) how do individual factors (e.g., personality, characteristics, language ability, self-perceptions, and attitudes) of Indian international students aid in their adjustment in the U.S?; and (2) can these individual factors be acquired by the students? This study intends to promote awareness among future Indian international students about individual factors that, when honed and developed could help in their successful adjustment to the academic and social life of the U.S.

\section{RESEARCH METHODS}

This study is a phenomenological qualitative research that involves understanding the essence of the phenomenon of the impact of individual factors on adjustment in the U.S. The experiences of the participants related to this phenomenon are explored in detail (Creswell, 2005; Creswell \& Poth, 2018).

\section{Sample}

With approval from Institutional Review Board, participants were recruited through the Office of International Student Services to participate in the study. Eighteen students responded to the email invitations, of which seven were selected using purposive sampling. According to Patton (1990), purposive sampling is a process where researcher selects participants who can provide rich information related to the topic under study. All the participants were born and raised in India. Of the total, there were four male and three female student participants, of which one student was a Master's, and the remaining were Ph.D. students. Their disciplines included Chemistry, Engineering, 
Economics, Biophysics, and Business. Their ages ranged from 24 to 45 years, and all of them have been staying in U.S. for over two years (Table $1)$.

Table 1. Study participants profiles

\begin{tabular}{|c|c|c|c|c|c|}
\hline Participants & Gender & Age & $\begin{array}{l}\text { No. of } \\
\text { Years } \\
\text { Stayed } \\
\text { in the } \\
\text { U.S. }\end{array}$ & Discipline & $\begin{array}{l}\text { Educational } \\
\text { Level }\end{array}$ \\
\hline Krishna & $\mathrm{M}$ & $\begin{array}{l}26 \\
\text { yrs. }\end{array}$ & 2 & Engineering & MS \\
\hline Shreya & $\mathrm{F}$ & $\begin{array}{l}24 \\
\text { yrs. }\end{array}$ & $21 / 2$ & Chemistry & Ph.D. \\
\hline Shruti & $\mathrm{F}$ & $\begin{array}{l}25 \\
\text { yrs. }\end{array}$ & $2 \frac{1}{2}$ & Economics & Ph.D. \\
\hline Pragya & $\mathrm{F}$ & $\begin{array}{l}28 \\
\text { yrs. }\end{array}$ & 3 & Biophysics & Ph.D. \\
\hline Rishi & $\mathrm{M}$ & $\begin{array}{l}31 \\
\text { yrs. }\end{array}$ & 5 & Physics & Ph.D. \\
\hline Vishnu & M & $\begin{array}{l}32 \\
\text { yrs. }\end{array}$ & 7 & Engineering & Ph.D. \\
\hline Arjun & M & $\begin{array}{l}45 \\
\text { yrs. }\end{array}$ & 11 & Business & Ph.D. \\
\hline
\end{tabular}

Initially, participants were sent a request email for a one-on-one meeting. The purpose of this meeting was to provide an opportunity for the participants to ask questions or express any of their concerns. Following this meeting, written consent forms were obtained from the participants and were explained the confidentiality procedures to be followed in this study. They were asked for permission to record and transcribe their interviews. All the participants were informed that they could withdraw at any time of the interview. Data for this article were extracted from an earlier study conducted at a public university located in a Southern state of the U.S. Specifically, the extracted data comprised of individual factors that helped in the adjustment of students from India to the life in U.S. 


\section{Trustworthiness}

To maintain the trustworthiness of the study, the Epoche process was employed, wherein Epoche refers to studying a phenomenon by excluding researchers' bias and assumptions (Husserl, 1931). Further, member checks were conducted, wherein the participants were again contacted to examine their transcribed interviews in case they wanted to make any changes to the transcriptions.

\section{Data Analysis}

Phenomenological methodology (Moustakas,1994) was employed to analyze the data for this study. Briefly, the authors applied an unbiased approach that was free of preconceived notions when listening to the interviews. After that, invariant constituents were identified that were crucial in understanding the phenomenon, while deleting vague and unclear statements. Meaningful invariant constituents were classified as themes that evolved into individual textural and structural descriptions that highlighted the "what" and "why" of the phenomenon under study. Individual descriptions were then combined as group experiences to explain the phenomenon from a general perspective of all participants in the study.

\section{RESULTS}

The data analysis revealed following ten individual factors that helped the participants to adjust to the academic and social life in the U.S.: 1) self-confidence 2) positive attitude 3) staying in touch with the family and making friends 4) keeping occupied 5) English language 6) maintaining originality 7) preparing in advance 8) having no expectations 9) understanding the need to be professional and 10) being polite. The findings also identified how these ten individual factors could be acquired by adapting certain cognitive and behavioral aspects, as illustrated in figures 1 and 2. Figure 2 is an extension of figure 1, indicating how certain cognitive and behavioral elements lead to respective individual factors, that in turn lead to outcomes contributing to successful student adjustment. 
Figure 1. The road map to a successful adjustment of students from India in the U.S.

\begin{tabular}{|c|c|c|c|}
\hline Cognitive and & Individual & Positive & Successful Adjustment \\
\hline Behavioral Aspects & Factors & Outcomes & of Students from India \\
\hline
\end{tabular}

Figure 2. Adjustment of Students from India in U.S. (extended version of Fig 1)

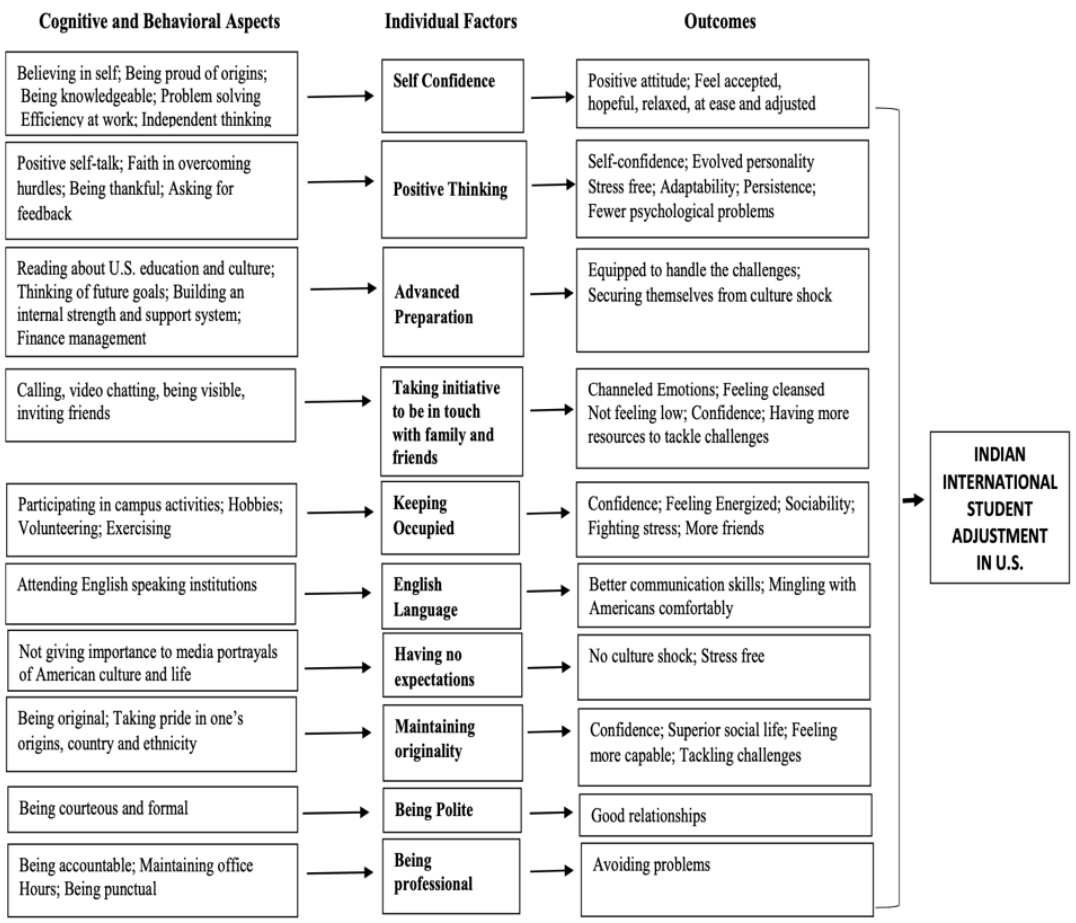

Self Confidence: Six participants explained how believing in themselves augmented their self-confidence, which in turn helped them successfully adjust to life in the U.S. For example, Shruti explained, "You have to be very confident in what you are as a person right in India itself. Trying to be somebody else might work for some time, but in the long run, I think it doesn't." Shruti's belief in being herself and doing things that she is most comfortable with, increased her confidence level when interacting 
with people. Likewise, Pragya explained, "The fact that I am so strong on my identity as an Indian, I think they like that and I feel more confident." Self-confidence developed positive attitude in Pragya. She felt accepted among her peers and became more hopeful about her life in the host country. Arjun's self-confidence helped him be himself, develop a relaxed attitude and be at ease in the host country. Explaining how he developed his selfconfidence, Arjun stated, "my passion for my subject and being knowledgeable in my field helped me gain respect from people, which in turn increased my self-confidence and self-esteem."

Shreya's efficiency at work enabled her to gain the confidence of her professors and enhanced her self-confidence. Cherishing this experience, she stated:

Initially when I came to the lab, my professor told me that he will see my work and depending on that, he will either hire me as a graduate student or not and then he gave me a month's time for that. So, I was given a project which I had no idea about. I started from scratch and I think he saw me for three days and on the fourth day, he said that he wants to hire me as a graduate student. I felt like an achiever.

For Rishi, developing independent thinking boosted his self-confidence that in turn helped in solving problems in the U.S.

Positive Attitude: Of the seven participants in the study, five mentioned how positive thinking helped them adjust to life in the U.S. In situations of generally encountered difficulties, Krishna engaged in positive self-talk. He told himself that he was confronting challenges because of the changes in the culture and lifestyle between India and the U.S. Explaining, he stated,

It's crucial to always have belief in that you will get over the situation. If you are not strong enough, then ask for help from your friends or relatives. Do NOT start questioning your decision to come to the U.S. because that is the wrong question to solve. Ask what makes you enjoy in the U.S. And once you answer that, you would know exactly what you need to do. 
Positive thinking augmented Krishna's self-confidence, helped him overcome challenges, and feel academically adjusted. Similarly, explaining the interrelation between positive thinking, confidence, and adjustment, Shruti stated,

I always worried about what people would think of me and how I would do certain things. But now, I am more confident about those things. I always used to think of the worst outcome. But now, although I think of the worst outcome, yet, I say to myself, 'it's ok, I can live with things.

Rishi's positive thinking developed through his habit of paying gratitude to others. He always thanked the U.S. for providing him with the opportunity to study at their university. Explaining this aspect, he stated:

Whenever I go and talk to Americans, I know I am an outsider. I never considered myself to be a part of this society, be in terms of language or culture or anything. Usually I talk with a sense of gratitude. I ask myself this question - suppose the same situation was reversed; let's say, this is India, you are an Indian and they are Americans, it's like role reversal, will you be so acceptable? Will you be so welcoming to other cultures? Will you be so forthcoming to help others? If you see everything in that light, then what you see is a service to you. So, in that sense I don't have any questions.

Positive attitude helped Rishi overcome constant fear of failing and not making good grades in his Ph.D. program. He reminded himself of his innate confidence, his ability to work hard, and his potential to achieve his Ph.D. degree, which in turn helped him feel secure and calm. Arjun's positivity was indicated in his creative ways to handle the challenges. He asked people for feedback on his English-speaking skills, his academic performance, and aspects to consider while socializing. Accordingly, he modified his behavior and abilities. Stating the outcome of this positive approach, he said, "I evolved with people's feedback." Additionally, upon facing a challenge, Arjun always thought of alternatives instead of giving up. Shruti's approach to encouraging positive thinking was to discourage her negative thoughts whenever she was faced with a challenge. 
Similarly, Shreya converted sad incidents into positive experiences. She used her problems as learning opportunities, applied the learned knowledge and continued with her academic and social life. These methods helped the participants to sustain a successful academic and social life in the U.S.

Preparing in Advance: Five of the participants shared their experiences regarding the importance of making advance preparations, which helped them adjust successfully to the academic and social life in the U.S. Arjun prepared himself by reading books on the educational, social and cultural life in the U.S. He learned that, "People coming from industry should be prepared to switch to academic mode which includes sleepless nights, tight finances and loads of classes." Similarly, Vishnu began his preparations much in advance. He attended his University group meetings in India itself. Explaining the advantages of advance preparation, he said,

I had already met people; spoke to people right in India; we had gotten to know each other; we came here as a group; I already knew my roommate fixed over there; and we had an apartment. I came to know of the India Association at my University, who helped us.

On a similar note, Rishi stated, "Now, if I go anywhere, I plan ahead, and I book, I inform, schedule, organize." To overcome his fear of failing, Rishi prepared himself by saying, "I have come this long to pursue Ph.D. and there is no way I was going back'." Also, he prepared people in advance. Explaining, he said, "Whenever I teach the course, I tell them that these are the words I have difficulty with, so please be aware of it."

Further, stating the advantages of advanced preparation, Rishi commented, "If you plan ahead, meet deadlines, think ahead, your career will be very smooth in the U.S." Like Rishi, Pragya too believed in advance thinking, "It is essential to start thinking in advance about the kind of person one wants to share an apartment with." She believed in thinking about the goal that needs to be achieved five years from now and accordingly work towards it diligently. Further, she talked about the psychological preparation: 
You have to be prepared to be homesick and lonely. Be prepared to disrupt your life from India completely; it's just not the same; you are not going to have festivals; you may not be able to go to temple. You have to build internal strength and be your own support system.

Likewise, emphasizing on psychological preparation, Krishna noted, "be aware that no matter what, you would go through a stress cycle. Be prepared and don't panic. Make loads of friends and don't restrict to people from the same country."

Staying in Touch with Family and Friends: Taking the initiative to stay in touch with family and friends helped the participants in managing their emotions and loneliness. Explaining this aspect, Krishna stated, "By keeping in touch with parents and friends back in India regularly, I stopped feeling that I was away from them. My emotions got a channel through my newfound friends." Pragya described,

Having a fiancé in the U.S. to rely on helped me a lot. I think, if he had not been here, I would have been a much more a miserable person. Also, socializing, having a change of scene, people; it definitely helps; it is cleansing.

Vishnu stated, "I had friends over here, which helped me emotionally. I don't feel low as I talk to my parents." Arjun continually invited his friends over. Talking and sharing jokes with them served as a stress buster for Arjun. Further, describing one of the methods to connect with people, Rishi noted,

Let's say, to write proposals, to write grants, you must be visible, you have to be seen outside your domain. For example, I see most students write email to first authors of the paper. That way, they know that, 'Yes this person is also working'. But, because I never communicated, nobody knows what I am doing and I am not visible. 
Keeping Occupied: Krishna delineated on how keeping himself occupied in various extra-curricular activities, along with studies, increased his self-confidence, productivity, and sociability. He mentioned,

I started keeping myself busy in studies, various campus activities and my hobbies such as photography. I took Chinese classes just for the fun sake. I knew that this all would also help me in fighting stress. And it worked. This helped me learn about American lifestyle and make more American friends.

Similarly, Arjun stated, "for me, the experience of volunteering helped." Analogously, Pragya kept herself occupied by exercising. Explaining, she said, "I would do cardio, weight training, and yoga. It helped me feel refreshed, rejuvenated and energized." She further kept occupied by learning about other crucial aspects of life in the U.S. through her interactions with Americans.

English Language: Krishna, Shreya, Shruti, Pragya, and Vishnu had all studied in schools where English was the medium of instruction, in India. As a result, they had no significant difficulties in communicating in English and understanding the American accent. Shreya stated, "It definitely helps to know English. I could explain things to people very well, which increased my self-confidence." Along similar lines, Pragya and Vishnu commented, "My ability to communicate in English helped me mingle with Americans comfortably."; "There was nothing about English language that really shocked me over here."

Having No Expectations: Some of the participants in the present study attributed their smooth transition to having no expectations. For instance, Shreya explained,

Do not keep too many expectations, just come over here with the mind that you are alone, you have to stand on your feet and take care of yourself; there is not going to be anybody to take care of you. If you expect too much, and then if it doesn't happen, then it's going to break you down. 
Maintaining Originality: Three of the study participants mentioned how being original, taking pride in their origins, country, and ethnicity promoted their confidence and helped them lead an advantageous social life. Describing this aspect, Shruti stated, "You have to be very confident in what you are as a person right in India itself. Trying to be somebody else might work for some time, but in the long run, I think it doesn't." Correspondingly, Pragya noted, "The fact that I am so strong on my identity as an Indian, I think they like that." "Honestly, one of the things I learned is just be yourself", indicated Vishnu.

Additionally, this study identified two additional individual factors, understated in the literature: 1) being polite, and 2) understanding the need to be professional.

Being Polite: For Shruti and Rishi, being polite, courteous, and formal helped them in formulating good and healthy relationships with faculty and people in general. Explaining, Rishi suggested, "you have to blend in into the culture to learn what is polite here, what is not polite here, what should be done, how should you ask for certain things, should you even ask for certain things." Likewise, Shruti said,

The rules that you follow with professors and relationships in India, I mean, though you cannot see the rules clearly here, if you are not sure, just stick to the most polite ways of doing things.

Understanding the need to be professional: Krishna and Rishi emphasized on being professional to have a smooth academic life. Krishna stated, "Do a bit of background reading; people should be prepared to be a bit more professional here." Similarly, Rishi described,

Even though you are a student, for example, you are given teaching responsibilities in U.S. I did not have that kind of outlook towards being a student in the US. That was the biggest discovery for me. 
For the first few semesters, I did not have that. But, if you don't have that, you are like doomed. I mean being answerable to the ones who gave you the job, even if it's just grading work, you have to do it professionally. If you maintain office hours, you have to maintain those office hours; you come at that time and leave at that time. These were things that I was not aware, but I was made to (smiles)

\section{DISCUSSION AND CONCLUSION}

All the six participants in this study indicated that when they worked towards augmenting their self-confidence, they possessed a heightened sense of belonging to the university, felt more hopeful, at ease, and consequently felt more adjusted to their host country. These findings concur with the previous literature that suggests that individuals with greater levels of confidence report more significant adjustment, less strain, and are more determined to succeed (Chemers, $\mathrm{Hu}$, \& Garcia, 2001; Moores \& Popadiuk, 2011; Wei et al, 2008). The participants of this study acquired their self-confidence by believing in themselves, being proud of their origins, reading books to become more knowledgeable, learning to solve problems for themselves, undergoing training to be efficient at work, and practicing being independent.

In addition to possessing self-confidence, five of the participants revealed that when they adopted a positive approach towards life, specifically in the host country, they developed higher levels of persistence, were more at ease, and were able to adapt more quickly to the host country. This finding is in congruence with previous studies that suggest that students who engaged in positive thinking remained stress-free, and reported fewer psychological health problems (Pritchard, Wilson, \& Yamnitz, 2007). Participants acquired positive attitude by engaging in positive self-talk, believing in overcoming difficulties, showing gratitude towards others and asking for feedback to work on their flaws.

Results indicated that when participants prepared themselves in advance such as reading about U.S. education and culture, thinking about their future goals and learning about financial management, they felt more secure, developed greater internal strength, and possessed higher coping skills when adjusting to the life in U.S. (Moores \& 
Popadiuk, 2011). Supporting advance preparation, Rabia and Hazza (2017) observed that to overcome the language difficulties commonly encountered by Arab international students, and to protect them from culture shock, they must be taught English much in advance in their home country. Similarly, Moores and Popadiuk (2011) found that more in-depth preparation benefits transitioning students. When the student's awareness about the host culture is augmented, they are more equipped to handle the challenges in the host country (DuBose, 2017; Moores \& Popadiuk, 2011).

The findings of this study, similar to previous reports, indicated a connection between adjustment and staying in touch with family and friends. Students who made friends and kept in touch with family were found to be more contented, developed higher levels of self-confidence, and possessed more resources to tackle challenges in the host country (Dennis, Phinney \& Chuateco; 2005). Further, such students possessed higher learning capabilities (Bista, 2015), were able to build a meaningful community (Moores \& Popadiuk, 2011), and were more committed to accomplishing their course goals and objectives (Nora \& Cabrera, 1996). Consequently, these students experienced less stress and more sense of adjustment in their academic and social settings (Enochs \& Roland, 2006; Hechanova-Alampay, Beehr, Christiansen \& Horn, 2002; Zhai, 2002). Participants acquired socializing skills by being more visible, attending various academic, cultural, and sports related events, mingling with national and international students, engaging in extracurricular activities, honing their language capabilities by seeking help from domestic students.

Participants reported that when they participated in extracurricular activities, such as getting involved in campus activities, hobbies, volunteering, and going to the gym, they developed a stronger sense of belonging to the university. They reported being more energized and had lower stress levels. These findings validate those of Ostrove and Long (2007), who found that students who do not participate in campus activities, do not feel integrated and accepted by their institution, which negatively impacts the students' academic, social, psychological, and physical well-being.

As anticipated, knowledge of the English language and possession of superior communication skills aided the participants to mingle with domestic counterparts comfortably. In an earlier report, DuBose (2017) found efficiency in English to be the most crucial aspect of successful student adjustment. On the other hand, lack of 
English language skills was found to hinder successful adaptation to the host country (Kamara, 2017; Rabia \& Hazza, 2017).

Further, when the study participants were more professional, such as maintained office hours, were punctual and accountable, they were able to avoid unforeseen problems and had rewarding academic adjustment. Similarly, when they were polite, such as being courteous and formal, they developed and maintained good relationships with fellow students and faculty. This, in turn, helped them in their psychological adjustment to the host country.

\section{LIMITATIONS}

One of the limitations of the present study is the small sample size, because of which the findings cannot be generalized across the Indian international student population. Despite the limitation, this study provides an in-depth understanding of the phenomenon of individual factors that aid in successful adjustment to the U.S. Additionally, the findings indicate how these individual factors can be acquired by the students. Similar future research is suggested with a larger sample size.

\section{REFERENCES}

Alsahafi, N., \& Shin, S. C. (2016). Factors affecting the academic and cultural adjustment of Saudi international students in Australian universities. Journal of International Students, 7(1), 53-72.

Bista, K. (2012). Silence in teaching and learning: Perspectives of a Nepalese graduate student. College Teaching, 60(2), 76-82.

Bista, K. (2015). Asian international students' college experience: Relationship between the quality of personal contact and gains in learning. Journal of International and Global Studies, 6(2), 39.

Chavoshi, S., Wintre, M.G., Dentakos, S., \& Wright, L. (2017). Developmental Sequence Model to University Adjustment of International Undergraduate Students. Journal of International Students, 7(3), 703-727. 
Chemers, M. M., Hu, L. T., \& Garcia, B. F. (2001). Academic selfefficacy and first-year college student performance and adjustment. Journal of Educational Psychology, 93(1), 55.

Costa Jr, P. T., \& McCrae, R. R. (1995). Domains and facets: Hierarchical personality assessment using the Revised NEO Personality Inventory. Journal of Personality Assessment, 64(1), 21-50.

Creswell, J. W. (2005). Research design: Qualitative and quantitative approaches. Thousand Oaks, CA: Sage.

Creswell, J. W., \& Poth, C. N. (2018). Qualitative inquiry and research design: Choosing among five approaches $\left(4^{\text {th }}\right.$ ed.).Thousand Oaks, CA: Sage.

Dennis, J. M., Phinney, J. S., \& Chuateco, L. I. (2005). The role of motivation, parental support, and peer support in the academic success of ethnic minority first-generation college students. Journal of College Student Development, 46(3), 223-236.

DuBose, C, O. (2017). But I don't understand you: One faculty's observations of the challenges facing international healthcare students. Journal of International Students, 7(1), 154-159.

Duru, E., \& Poyrazli, S. (2007). Personality dimensions, psychosocialdemographic variables, and English language competency in predicting the level of acculturative stress among Turkish international students. International Journal of Stress Management, 14, 99-110.

Enochs, W. K., \& Roland, C. B. (2006). Social adjustment of college freshmen: the importance of gender and living environment. College Student Journal, 40(1).

Gershuny, B. S., \& Sher, K. J. (1998). The relation between personality and anxiety: findings from a 3-year prospective study. Journal of Abnormal Psychology, 107(2), 252.

Gomez, E., Urzua, A., \& Glass, C.R. (2014). International student adjustment to college: Social networks, acculturation, and leisure. Journal of Park and Recreation Administration, 32(1), 7-25. 
Hechanova-Alampay, R., Beehr, T. A., Christiansen, N. D., \& Van Horn, R. K. (2002). Adjustment and strain among domestic and international student sojourners: A longitudinal study. School Psychology International, 23, 458-474.

Hendrickson, B., Rosen, D., \& Aune, RK (2011). An analysis of friendship networks, social connectedness, homesickness, and satisfaction levels of international students. International Journal of Intercultural Relations, 35(3), 281-295.

Hirai, R., Frazier, P., \& Syed, M. (2015). Psychological and sociocultural adjustment of first-year international students: Trajectories and predictors. Journal of Counselling Psychology, 62(3), 438.

Husserl, E. (1931). Ideas (W. R. Boyce Gibson, Trans.). London: George Allen \& Unwin.

Institute of International Education. (2018). Open doors 2018: All places of origin. International student data. https://www.iie.org/Research-and-Insights/OpenDoors/Data/International-Students/Places-of-Origin. Retrieved on May 04, 2019.

Kamara, A. (2017). International students and "The Presentation of Self" across cultures. Journal of International Students, 7(2), 291310.

Kaur, D. (2006). International students and American higher education: A study of the academic adjustment experiences of six Asian Indian international students at a research level II University (Doctoral dissertation, The University of North Carolina at Charlotte, 2006). ProQuest LLC, (UMI No. 3239820).

Lee, J. J., \& Rice, C. (2007). Welcome to America? International student perceptions of discrimination. Higher Education, 53(3), 381409.

Li, A., \& Gasser, M. B. (2005). Predicting Asian international students sociocultural adjustment: A test of two mediation models. International Journal of Intercultural Relations, 29, 561-576.

Magnus, K., Diener, E., Fujita, F., \& Pavot, W. (1993). Extraversion and neuroticism as predictors of objective life events: A longitudinal analysis. Journal of Personality and Social Psychology, 65(5), 1046. 
Martinez, M. L., \& Colaner, K. T. (2017). Experience of International Education of East Asian Students in English-speaking Countries: A four-dimensional approach. Journal of Student Affairs in Africa, 5(1), 15-26.

Moores, L \& Popadiuk, N. (2011). Positive aspects of international student transitions: A qualitative inquiry. Journal of College Student Development, 52 (3), 291-306.

Mori, S. (2000). Addressing the mental health concerns of international students. Journal of Counselling and Development, 78, 137144.

Moustakas, C. (1994). Phenomenological Research Methods. Thousand Oaks, CA: Sage.

Nora, A., \& Cabrera, A.F. (1996). The role of perceptions of prejudice and discrimination on the adjustment of minority students to college. The Journal of Higher Education, 67(2), 119-148.

Ostrove, J. M., \& Long, S. M. (2007). Social class and belonging: Implications for college adjustment. The Review of Higher Education, 30(4), 363-389.

Patton, M. Q. (1990). Qualitative Evaluation Methods (2nd ed.). Beverley Hills, CA: Sage.

Poulakis, M., Dike, C.A., \& Massa, A.C. (2017). Acculturative stress and adjustment experiences of Greek international students. Journal of International Students, 7(2), 204-228.

Poyrazli, S., Kavanaugh, P.R., Baker, A., \& Al-Timimi, N. (2004).

Social support and demographic correlates of acculturative stress in international students. Journal of College Counselling, 7, 73-82.

Poyrazli, S., Thukral, R. K., \& Duru, E. (2010). International student's race-ethnicity, personality, and acculturative stress. International Journal of Psychology and Counselling, 2(2), 2532.

Pritchard, M.E., Wilson, G.S., \& Yamnitz, B. (2007). What predicts adjustment among college students? A longitudinal panel study. Journal of American College Health, 56, 15-21. 
Rabia, A., \& Hazza, M. (2017). Undergraduate Arab International Students' Adjustment to US Universities. International Journal of Higher Education, 6(1), 131-139.

Robertson, M., Line, M., Jones, S., \& Thomas, S. (2000). International students, learning environments, and perceptions: A case study using the Delphi technique. Higher Education Research \& Development, 19(1), 89-102.

Roesch, S. C., Wee, C., \& Vaughn, A. A. (2006). Relations between the Big Five personality traits and dispositional coping in Korean Americans: Acculturation as a moderating factor. International Journal of Psychology, 41(2), 85-96.

Rui, J. R., \& Wang, H. (2015). Social network sites and international students' cross-cultural adaptation. Computers in Human Behavior, 49, 400-411.

Sam, D. L. (2001). Satisfaction with life among international students: An exploratory study. Social Indicators Research, 53(3), 315337.

Searle, W., \& Ward, C. (1990). The prediction of psychological and sociocultural adjustment during cross-cultural transitions. International Journal of Intercultural Relations, 14, 449-464.

Shupe, E. I. (2007). Clashing cultures: A model of international student conflict. Journal of Cross-Cultural Psychology, 38 (6), 750771 .

Swagler, M. A., \& Ellis, M.V. (2003). Crossing the distance: Adjustment of Taiwanese graduate students in the United States. Journal of Counselling Psychology, 50, 420-437.

Swagler, M. A., \& Jome, L. M. (2005). The Effects of Personality and Acculturation on the Adjustment of North American Sojourners in Taiwan. Journal of Counselling Psychology, 52(4), 527.

Ward, C., Bochner, S. \& Furnham, A. (2001). The Psychology of Culture Shock. London: Routledge.

Ward, C., Leong, C. H., \& Low, M. (2004). Personality and sojourner adjustment: An exploration of the Big Five and the cultural fit 
proposition. Journal of Cross-Cultural Psychology, 35(2), 137151.

Wei, M., Ku, T. Y., Russell, D. W., Mallinckrodt, B., \& Liao, K. Y. H. (2008). Moderating effects of three coping strategies and selfesteem on perceived discrimination and depressive symptoms: A minority stress model for Asian international students. Journal of Counselling Psychology, 55(4), 451.

Yeh, C. J., \& Inose, M. (2003). International students' reported English fluency, social support satisfaction, and social connectedness as predictors of acculturative stress. Counselling Psychology Quarterly, 16(1), 15-28.

Ying, Y. W. (2002). Formation of cross-cultural relationships of Taiwanese international students in the United States. Journal of Community Psychology, 30(1), 45-55.

Zhai, L. (2002). Studying International Students: Adjustment Issues and Social Support.

Zhou, J., \& Cole, D. (2017). Comparing international and American students: involvement in college life and overall satisfaction. Higher Education, 73(5), 655-672.

PRASHANTI CHENNAMSETTI holds a PhD in Educational Administration and Human Resources from Texas A\&M University. She served as an adjunct faculty at WKU-Owensboro. She is passionate about conducting Needs Assessment using phenomenological methodology. Her research interests also include international student learning and adjustment in higher education, workplace learning, impact of positive thinking, and factors that impact employee productivity and satisfaction. She was selected as a Gallup International Positive Psychology fellow with faith in her ability to bring positive change in people's lives, workplaces, schools, and communities. Email: prashantichennamsetti@gmail.com

KRISHNA BISTA, Ed. D, is an Associate Professor in the Department of Advanced Studies, Leadership and Policy at 
Morgan State University. His research focuses on college student experiences related to classroom participation, perceptions of academic integrity, faculty-student relationships, role of advisors, and cross-cultural teaching and learning strategies in higher education. Previously, Dr. Bista served as the director of Global Education at the University of Louisiana at Monroe, where he was Chase Endowed Professor of Education in the School of Education. Email: krishna.bista@morgan.edu 